\title{
Transient Studies on Carbon Monoxide Oxidation over Supported Gold Catalysts:
}

\section{Support Effects}

Maria Olea $^{1 *}$ and Yasuhiro Iwasawa

Department of Chemistry, Graduate School of Science, The University of Tokyo, Hongo,

Bunkyo-ku, Tokyo 113-0033, Japan

Running title: TAP studies on carbon monoxide oxidation over supported gold catalysts

*Corresponding author: Tel. +3292644538 Fax +329264 4999

E-mail: $\quad$ Maria.Olea@,UGent.be

\footnotetext{
${ }^{1}$ Present address:

Laboratorium voor Petrochemische Techniek, Ghent University, Krijgslaan 281 S5, 9000 Ghent, Belgium 


\begin{abstract}
The origin of support effects on the activity of supported gold catalysts was examined in details via the Temporal Analysis of Products (TAP) approach. Supported catalysts derived from interaction of an Au-phosphine complex $\mathrm{Au}\left(\mathrm{PPh}_{3}\right)\left(\mathrm{NO}_{3}\right)$ with as-precipitated titanium hydroxide $\mathrm{Ti}(\mathrm{OH})_{4}{ }^{*}$ afforded remarkably high catalytic activity for low-temperature carbon monoxide oxidation compared to catalysts obtained by supporting $\mathrm{Au}\left(\mathrm{PPh}_{3}\right)\left(\mathrm{NO}_{3}\right)$ to conventional titanium oxide $\mathrm{TiO}_{2}$. At $300 \mathrm{~K}$, for a carbon monoxide to oxygen 1:1 ratio, carbon monoxide conversion was $50 \%$ on $\mathrm{Au} / \mathrm{Ti}(\mathrm{OH})_{4}{ }^{*}$ catalyst, but $1 \%$ only on $\mathrm{Au} / \mathrm{TiO}_{2}$. Single-pulse TAP experiments evidenced that, among the other factors, morphology and specific surface area of catalyst supports have an influence on intraparticle diffusion and adsorption features, which in turn have an influence on the reaction rate. While for the mesoporous $\mathrm{Au} / \mathrm{Ti}(\mathrm{OH})_{4}{ }^{*}$ catalyst, its internal surface area is efficiently utilized equally to the external surface for carbon monoxide oxidation, for the microporous $\mathrm{Au} / \mathrm{TiO}_{2}$ catalyst, carbon monoxide oxidation reaction occurs pre-eminently on the external surface, because the internal diffusion was extremely slow. Based on pulse-response results, a new method to determine the intraparticle Knudsen diffusivity, $\mathrm{D}_{\mathrm{p}}$, was proposed. For argon on $\mathrm{Au} / \mathrm{TiO}_{2}$, $1.4 \times 10^{-7} \mathrm{~cm}^{2} \mathrm{~s}^{-1} \mathrm{D}_{\mathrm{p}}$ calculated value was in good agreement with values reported in literature.
\end{abstract}

Key Words: supported gold catalyst, carbon monoxide oxidation, reaction mechanism, isotopic exchange, TAP studies, inter and intraparticle Knudsen diffusion 


\section{Introduction}

Gold has long been considered to be inert as a catalyst for most reactions. However, recent studies have demonstrated that highly dispersed gold particles supported on reducible oxides such as $\mathrm{TiO}_{2}, \mathrm{Fe}_{2} \mathrm{O}_{3}, \mathrm{Co}_{3} \mathrm{O}_{4}$, and $\mathrm{NiO}$ [1-18] are very active in low-temperature carbon monoxide oxidation. It is now documented that the activity of supported gold catalysts for carbon monoxide oxidation is sensitive to the nature of supports $[9,18]$, the size of gold particles $[9,19]$, and the properties of the gold-support interface $[9,19,20]$, which all strongly depend on the method of preparation $[9,10,19]$. Although many studies have been carried out, the way in which the nature of support influence the nature of active species and reaction mechanism still remain unclear. As transient techniques (and TAP is one of them), have the advantage of providing more information about the possible intermediates involved in a adsorption or reaction mechanism, as well as about the rate coefficients of the related elementary steps, they were applied with good results for the study of low-temperature carbon monoxide oxidation over supported gold catalysts.

We have reported TAP studies [21,22] on diffusion and on carbon monoxide, oxygen, and carbon dioxide adsorption as well as catalytic carbon monoxide oxidation over a newlydeveloped titania-supported gold catalyst (denoted as $\mathrm{Au} / \mathrm{Ti}(\mathrm{OH})_{4}{ }^{*}$ ), which was tremendously active for low-temperature carbon monoxide oxidation. The followings were shown: carbon monoxide molecules reversibly and weakly adsorbed on the catalyst surface; oxygen adsorbed molecularly and strongly for high pulse intensities, with a lifetime of 4500-6900 ms at 373$423 \mathrm{~K}$; reaction occurred between adsorbed carbon monoxide and adsorbed molecular oxygen; lattice oxygen atoms were active in oxygen exchange only with carbon dioxide. Our TAP results confirmed the previously reported carbon monoxide oxidation mechanism on the catalyst $[7,23]$. 
In this study we focused our attention to understand the effect of the support on the performance of supported gold catalysts. For this purpose the behavior of a conventional $\mathrm{Au} / \mathrm{TiO}_{2}$ catalyst in carbon monoxide oxidation was examined by the TAP technique and compared with that of the $\mathrm{Au} / \mathrm{Ti}(\mathrm{OH})_{4}{ }^{*}$ catalyst. Single-pulse transient experiments were performed to investigate the diffusion of $\mathrm{Ar}$ and $\mathrm{He}$, and the adsorption of $\mathrm{CO}, \mathrm{O}_{2}$, and $\mathrm{CO}_{2}$. Pump-probe (alternating) TAP experiments were conducted to explore the behavior and lifetime of active oxygen species. The obtained data and knowledge can give insights into the origin of unique catalytic performance and may provide a new concept of catalyst design [11].

\section{Experimental}

All experiments were conducted using the TAP reactor system which has been described in detail elsewhere $[21,22]$. Briefly, the TAP system consists of a fast-pulse gas delivery system, a fixed-bed micro-reactor, and a computer-controlled real-time quadrupole mass spectrometer (Spectra Co.). All of them are located in three high-vacuum chambers, the chambers being connected by small pinholes. The base pressures of the chambers are $1,10^{-6}$, and $10^{-8} \mathrm{~Pa}$, respectively. The micro-reactor is made from a stainless steel tube whose diameter and length are $2 \mathrm{~mm}$ and $25 \mathrm{~mm}$, respectively. The powder catalytic material was palletized and sieved before using in TAP experiments. Throughout this study, the $250-425 \mu \mathrm{m}$ fraction was loaded and was fixed in the reactor by stainless steel meshes. When the reactor is completely filled with catalyst, the overall sample weight is $0.03 \mathrm{~g}$ and the length of the catalyst in the tube is $10 \mathrm{~mm}$. The reactor is heated by cartilage heaters which allow an isothermal operation.The two high-speed pulse valves can be operated at the interval up to 50 pulses per second. The minimum pulse width is 200 micro-second. The pulse intensities were varied between $10^{13}$ and $10^{20}$ molecules per pulse. Before each experiment the catalyst was heated at 
$473 \mathrm{~K}$ for $30 \mathrm{~min}$ in vacuum to desorb preadsorbed species. The 150 to 250 pulses in the TAP experiments were averaged to increase the signal-to-noise ratio in the response.

The preparation of $\mathrm{Au} / \mathrm{Ti}(\mathrm{OH})_{4}{ }^{*}$ catalyst has been described in detail elsewhere [2-6]. Asprecipitated wet titanium hydroxide $\mathrm{Ti}(\mathrm{OH})_{4}{ }^{*}$ was obtained by hydrolysis of $\operatorname{Ti}\left(\mathrm{O}^{\mathrm{i}} \mathrm{C}_{3} \mathrm{H}_{7}\right)_{4}$ (99.999\% purity) with an aqueous $\mathrm{NH}_{3}$ solution. The precipitate was then filtrated and washed with deionized water until the $\mathrm{pH}$ value became 7.0. The as-precipitated wet $\mathrm{Ti}(\mathrm{OH})_{4}{ }^{*}$ was impregnated with an acetone solution of $\mathrm{Au}\left(\mathrm{PPh}_{3}\right)\left(\mathrm{NO}_{3}\right)$ under vigorous stirring, followed by vacuum drying to remove the solvent at room temperature. The obtained sample was heated to $673 \mathrm{~K}$ at a ramping rate of $4 \mathrm{~K} \mathrm{~min}^{-1}$ and kept at this temperature for $4 \mathrm{~h}$ in a flow of air $(30 \mathrm{ml} / \mathrm{min})$. The calcination of the sample led to decomposition of both precursors, $\mathrm{Au}\left(\mathrm{PPh}_{3}\right)\left(\mathrm{NO}_{3}\right)$ and $\mathrm{Ti}(\mathrm{OH})_{4}{ }^{*}$, to metallic Au particles and $\mathrm{TiO}_{2}$, respectively. The catalyst thus obtained is denoted as $\mathrm{Au} / \mathrm{Ti}(\mathrm{OH})_{4}{ }^{*}$ where the term $\mathrm{Ti}(\mathrm{OH})_{4}{ }^{*}$ is used to clarify the origin of titanium oxide, discriminating the preparation of the present catalyst from that of conventional $\mathrm{Au} / \mathrm{TiO}_{2}$ catalysts. The use of as-precipitated wet $\mathrm{Ti}(\mathrm{OH})_{4}{ }^{*}$ as precursor was decisive in obtaining the more active catalyst [4,5-23].

A $\mathrm{Au} / \mathrm{TiO}_{2}$ catalyst was prepared by an incipient wetness impregnation method. $\mathrm{TiO}_{2}$ (Degussa P-25) was impregnated with an acetone solution of $\mathrm{Au}\left(\mathrm{PPh}_{3}\right)\left(\mathrm{NO}_{3}\right)$ under vigorous stirring, followed by drying in vacuum to remove the solvent at room temperature. The obtained sample was heated to $673 \mathrm{~K}$ at a ramping rate of $4 \mathrm{Kmin}^{-1}$ and kept at $673 \mathrm{~K}$ for $4 \mathrm{~h}$ in a flow of air $[4,5]$.

The gold loading on both supports was controlled to be $3.0 \mathrm{wt} \%$. 


\section{Results and discussion}

\subsection{Single-pulse experiments}

It is well known that gas transport through the catalyst bed in the TAP reactor is due only to Knudsen diffusion, since gas pulses are sufficiently small. To be sure that indeed only Knudsen diffusion occurs, single-pulse experiments using $\mathrm{Ar}$ and $\mathrm{He}$ as non-adsorbing gases have been performed on the $\mathrm{Au} / \mathrm{TiO}_{2}$ catalyst at 300, 400 and $600 \mathrm{~K}$. The fact that the shape of response curves was independent of the pulse sizes means that only Knudsen diffusion occurred. But when we compared the Ar response curve on $\mathrm{Au} / \mathrm{Ti}(\mathrm{OH})_{4}{ }^{*}$ with the one on $\mathrm{Au} / \mathrm{TiO}_{2}$ under the identical conditions (Fig. 1), we observed that the Ar response curve on $\mathrm{Au} / \mathrm{TiO}_{2}$ was broader than that on $\mathrm{Au} / \mathrm{Ti}(\mathrm{OH})_{4}{ }^{*}$. The same conditions meant the same pulse size, the same bed length, the same catalyst particle size, the same temperature, and the same weight of sample. This difference could be due to a different diffusivity of Ar through the catalyst beds. It is obvious that the diffusivity of $\mathrm{Ar}$ through the conventional $\mathrm{Au} / \mathrm{TiO}_{2}$ catalyst is smaller than the diffusivity of $\mathrm{Ar}$ through the active $\mathrm{Au} / \mathrm{Ti}(\mathrm{OH})_{4}{ }^{*}$ catalyst. To explain this difference we assumed that the behavior of the conventional catalyst was similar to that of a porous material, while the newly-developed catalyst behaved like a non-porous material. While the gas transport through a catalytic bed of non-porous material is described by the interparticles Knudsen diffusivity, two diffusivities are needed to describe the gas transport of a single component in the Knudsen diffusion regime for the TAP micro-reactor packed with porous particles. A diffusivity is used to describe Knudsen diffusion through the catalyst bed, while another diffusivity describes the diffusion in the catalyst particles [24]. As our TAP reactor is packed only with catalyst particles, we can describe the behavior of the catalyst bed during the gas pulse by so called "one-zone" model. In the case of porous catalysts the mathematical model must account for the following transport steps: (a) Knudsen 
diffusion of a gas component through the catalyst bed, (b) Knudsen diffusion of the gas component in the catalyst particles, and (c) linear adsorption and desorption of the gas component on the inner surface of the catalyst particles [24-27]. The time-dependent flux for species $\mathrm{A}$ at the microreactor exit can be obtained by solving a set of material balance equations. As in the case of non-porous particles [28], moments of the TAP response curve can be related to various model parameters. The final expression for the first absolute moment is [24]:

$$
t_{r e s}=\frac{L^{2} \varepsilon_{b}}{2 D_{L}}\left(1+2 \frac{l_{0}^{*}}{L \varepsilon_{b}}+\frac{1-\varepsilon_{b}}{\varepsilon_{b}}\left(\beta+\rho_{p} K_{a d}\right)\right) .
$$

As $\mathrm{Ar}$ is inert (hence neither adsorption, desorption nor reaction occur) and as $1_{0}{ }^{*}$ is assumed to be zero for $0.03 \mathrm{~g}$ of catalyst loaded in the reactor, the above equation can be simplified, and the effective Ar Knudsen diffusivity in the catalyst bed, $\mathrm{D}_{\mathrm{LAr}}$, can be determined. For $300 \mathrm{~K}, \varepsilon_{\mathrm{b}}=0.23$, and $\beta=0.12$ (experimentally determined), the value was calculated to be $0.077 \mathrm{~cm}^{2} \mathrm{~s}^{-1}$, which means 1.8 times lower than that for the $\mathrm{Au} / \mathrm{Ti}(\mathrm{OH})_{4}{ }^{*}$ catalyst. As expected, a square root temperature dependency in the diffusivity was found, $\mathrm{D}_{\mathrm{e}, \mathrm{Ar}}=0.0004 \mathrm{~T}^{1 / 2}+0.0697$ with $\mathrm{R}^{2}=0.0 .9979$. It seems that the internal porosity is important in gas flow and hence in catalytic reaction in the case of $\mathrm{Au} / \mathrm{TiO}_{2}$ catalyst. If we compare the experimental Ar response curve on the conventional catalyst with a standard diffusion curve for a non-porous catalyst (or model-predicted curve) which has the same effective Knudsen diffusivity in the catalyst bed we can observe a large difference between the two curves, as shown in Fig. 1. The fitting of the experimental curve with the modelpredicted curve was almost perfect for the $\mathrm{Au} / \mathrm{Ti}(\mathrm{OH})_{4}{ }^{*}$ catalyst as shown in our previous TAP results [21] and Fig. 1 as well. It means that the interior surface of the $\mathrm{Au} / \mathrm{Ti}(\mathrm{OH})_{4}{ }^{*}$ catalyst is as effective as the outer, that is, the newly-developed catalyst behaves as a non- 
porous material. In this case it would not be necessary to consider the problem of diffusion into the pores. The availability of the interior of the particles for catalysis depends upon the size, shape and permeability of pore structure. It is required for high effectiveness that the pores and capillaries are large and reasonably uniform and are interconnected with the external surface of the particles.

In other words the size of internal pores must be larger in the case of $\mathrm{Au} / \mathrm{Ti}(\mathrm{OH})_{4}{ }^{*}$ than in the case of $\mathrm{Au} / \mathrm{TiO}_{2}$. Indeed, the former physical characterization of the catalysts calcinated at $673 \mathrm{~K}$ revealed that the $\mathrm{Au} / \mathrm{Ti}(\mathrm{OH})_{4}{ }^{*}$ catalyst exhibited a mesoporous structure (meso-pores $>10 \mathrm{~nm}$ in diameter) with a surface area of $80 \mathrm{~m}^{2} \mathrm{~g}^{-1}$, while the $\mathrm{Au} / \mathrm{TiO}_{2}$ catalyst exhibited a microporous structure (micro-pores $<2 \mathrm{~nm}$ in diameter) with a surface area of $103 \mathrm{~m}^{2} \mathrm{~g}^{-1}[19]$.

Moreover, we observed that the difference between He standard diffusion curve (assuming a non-porous catalyst) and $\mathrm{He}$ experimental diffusion curve on $\mathrm{Au} / \mathrm{TiO}_{2}$ was smaller than in the case of Ar. The interior surface of the catalyst was more effective for the diffusion of He molecules, which have a small size as compared with Ar ones. For the He diffusion, $\mathrm{D}_{\mathrm{LHe}}$ at $300 \mathrm{~K}$ was $0.090 \mathrm{~cm}^{2} \mathrm{~s}^{-1}$. Figure 2 presents the comparison between experimental and modelpredicted TAP responses in the case of He diffusion.

Now we can determine the effective Knudsen diffusivity in the catalyst bed for $\mathrm{O}_{2}, \mathrm{CO}$, and $\mathrm{CO}_{2}$. As the effective Knudsen diffusivity linearly depends on the $1 / \sqrt{M}$ [29], we can determine the values of diffusivity of those molecules using the values of diffusivity for Ar and $\mathrm{He}$ on the conventional $\mathrm{Au} / \mathrm{TiO}_{2}$ catalyst. $D_{L O_{2}}, D_{L C O}$, and $D_{L C O_{2}}$ were $0.0777 \mathrm{~cm}^{2} \mathrm{~s}^{-1}$, $0.0782 \mathrm{~cm}^{2} \mathrm{~s}^{-1}$, and $0.0767 \mathrm{~cm}^{2} \mathrm{~s}^{-1}$, respectively. $\mathrm{On} \mathrm{Au} / \mathrm{Ti}(\mathrm{OH})_{4}{ }^{*}$ catalyst, the values for the same parameters were $0.157 \mathrm{~cm}^{2} \mathrm{~s}^{-1}, 0.168 \mathrm{~cm}^{2} \mathrm{~s}^{-1}$, and $0.133 \mathrm{~cm}^{2} \mathrm{~s}^{-1}[21]$.

As far as the adsorption/desorption phenomena is concerned, single-pulse TAP experiments on the $\mathrm{Au} / \mathrm{TiO}_{2}$ catalyst revealed other differences. Comparing the response 
curves of $\mathrm{O}_{2}, \mathrm{CO}$, and $\mathrm{CO}_{2}$ on $\mathrm{Au} / \mathrm{TiO}_{2}$ with the response curves of the inert gases, we can say that reversible and weak adsorption occurred for all three gases as shown in Fig. 3, at both low and high pulse intensities. The signals for $\mathrm{O}_{2}$ and $\mathrm{CO}_{2}$ were almost the same as that for Ar, which is a non-adsorbing gas under the TAP conditions. The results indicate that the equilibrium constants for the adsorption of these gases are too small to be determined. A larger amount of sample may allow to determine a very small equilibrium constant for adsorption [27], but we have already used the maximum amount of sample $(0.03 \mathrm{~g})$ that can be accommodated in the reactor.

By using eq. (1), we have tried to determine the $\mathrm{K}_{\mathrm{ad}}$ for $\mathrm{O}_{2}, \mathrm{CO}$, and $\mathrm{CO}_{2}$. From the equilibrium constants for adsorption determined in the adsorption/diffusion experiments, the heat of adsorption and the pre-exponential factor $v_{\mathrm{ad}}$ can be determined by a van't Hoff plot using eq. (2):

$K_{a d}=v_{a d} e^{-\Delta H_{a d} / R T}$

Thermodynamic parameters were determined for $\mathrm{O}_{2}$ and $\mathrm{CO}$ whereas for $\mathrm{CO}_{2}$ the difference in the response curve between $\mathrm{CO}_{2}$ and $\mathrm{Ar}$ was too small and hence, $\mathrm{K}_{\mathrm{ad}}$ could not be determined. The results are given in Table 1 . It can be seen that the heat of adsorption is very low, especially in the case of oxygen adsorption. It means that indeed, on the conventional catalyst, most of the oxygen is just weakly and reversibly adsorbed .

Our previous TAP studies on $\mathrm{Au} / \mathrm{Ti}(\mathrm{OH})_{4}{ }^{*}$ proved that oxygen at high pulse intensities and carbon dioxide exhibited very strong (reversible) adsorption on this catalyst $[21,22]$. But for low pulse intensities, the oxygen adsorption was weak and reversible. Weak and reversible was the carbon monoxide adsorption as well. However, the adsorption equilibrium constants on $\mathrm{Au} / \mathrm{Ti}(\mathrm{OH})_{4}{ }^{*}$ were about ten times higher than adsorption equilibrium constants on $\mathrm{Au} / \mathrm{TiO}_{2}$. It means a higher probability to react in the adsorbed states. 
It has been proved $[18,22,23]$ that oxygen adsorbed molecularly on oxygen vacancies at the titanium oxide surface in the form of superoxide, $\mathrm{O}_{2}{ }^{-}$, and carbon monoxide molecules adsorbed on both $\mathrm{Au}$ particles and $\mathrm{Ti}^{4+}$. Only the carbon monoxide molecules adsorbed on gold and the $\mathrm{O}_{2}{ }^{-}$species on oxygen vacancies adjacent to the Au particles were responsible for the catalytic carbon monoxide oxidation. It was also found [5,19] that states of the mesoporous support precursor upon attaching the gold precursor onto them and during the temperature-programmed calcination appeared to be of great importance in obtaining dispersed gold nanoparticles on oxide surfaces. The smaller the gold particles' size, the higher the activity towards low-temperature carbon monoxide oxidation. Indeed, the mean diameter of gold particles in $\mathrm{Au} / \mathrm{Ti}(\mathrm{OH})_{4}{ }^{*}$ calcined at $673 \mathrm{~K}$ was found to be less than $30 \AA$, which was about one-tenth of that for the $\mathrm{Au} / \mathrm{TiO}_{2}$ [5]. The slower diffusion of $\mathrm{O}_{2}$ and $\mathrm{CO}$ on $\mathrm{Au} / \mathrm{TiO}_{2}$, the lower adsorption equilibrium constants of $\mathrm{O}_{2}$ and $\mathrm{CO}$ on this catalyst and the higher gold particle size of the same catalyst explained the lower reaction rate compared to that obtained on $\mathrm{Au} / \mathrm{Ti}(\mathrm{OH})_{4}{ }^{*}$, for activation energies of the same order of magnitude. For $\mathrm{Au} / \mathrm{TiO}_{2}$ catalyst, $\mathrm{E}_{\mathrm{a}}$ was reported to be $2.9 \mathrm{kcal} \mathrm{mol}^{-1}$ [8]. Reaction rate, expressed as mol CO (mol-Au$)^{-1} \mathrm{~s}^{-1}$ catalyst was found to be $9.6 \times 10^{-3}$ and conversion $58 \%$ over $\mathrm{Au} / \mathrm{Ti}(\mathrm{OH})_{4}{ }^{*}$ catalyst, while for $\mathrm{Au} / \mathrm{TiO}_{2}$ the value was $1.2 \times 10^{-3}$ and conversion $7 \%$, values determined from steady-state experiments, for a $\mathrm{CO}: \mathrm{O}_{2}$ ratio $=1: 1$ [8]. For TAP single-pulse experiments with a $\mathrm{CO} / \mathrm{O}_{2}$ mixture in a 1:1 ratio, the determined conversion at $300 \mathrm{~K}$ was $50 \%$ on $\mathrm{Au} / \mathrm{Ti}(\mathrm{OH})_{4}{ }^{*}$ catalyst, but $1 \%$ only on $\mathrm{Au} / \mathrm{TiO}_{2}$. There is a small difference between the values of conversion determined from steady-state experiments and from TAP experiments. This can be explained by the pressure gap from atmospheric pressure in steady-state to high vacuum in transient experiments. 
Using TAP experiments, we could also determine the Knudsen diffusivity inside the particles. The limits for Knudsen diffusivity in the bed and Knudsen diffusivity inside the particle can be determined by the relative time constant of the diffusion into the particles compared to the time constant of the diffusion through the catalyst bed. Time constant for diffusion into particles is proportional to $\mathrm{r}_{\mathrm{p}}{ }^{2} / \mathrm{D}_{\mathrm{p}}$, while time constant for gas transport through the catalyst bed is proportional to $\mathrm{L}^{2} / \mathrm{D}_{\mathrm{L}}$. In fact, time constant for the diffusion into the particles is proportional to the pore length. But, the pore length strongly depends on the particle size. Moreover, it is known that a way to reduce resistance to pore diffusion is to reduce the particle size of catalyst thus shortening the diffusion path. If the reactor is loaded with only a small amount of catalyst, about $0.01 \mathrm{~g}$, the TAP reactor can be modeled as a "thin-zone TAP reactor" [30]. In a thin-zone reactor, the thickness of the catalyst zone is very small compared to the whole length of the reactor. Comparing the Ar response curve obtained in the empty reactor with that obtained in the thin-zone reactor, we have observed that the shape of two curves are almost the same (Fig. 4). A little delay appears when the reactor is loaded with $0.01 \mathrm{~g}$ of $\mathrm{Au} / \mathrm{TiO}_{2}$. Since no particles are present in the empty reactor, the average characteristic distance in this zone is equal to the inner diameter of the reactor. Since the inner diameter is much larger than the particle diameter in the thin-zone reactor, the diffusion coefficient in this zone is larger compared to the diffusion coefficient in thin-zone reactor. In the case of empty reactor the gas approaches perfect backmixing $[24,26,27]$ and therefore the response curve could be fitted by an exponential one. Using a fitting procedure, we obtained the equation of the unit area normalized exit flow (E curve, in $\mathrm{ms}^{-1}$ ) as follows:

$E=A \exp (-B t)$

where $\mathrm{A}=4.852 \mathrm{e}-4, \mathrm{~B}=4.556 \mathrm{e}-4$ and $\chi^{2}=8.33 \mathrm{e}-6$ (where $\chi^{2}$ is the merit function given by the sum of squared residuals). From the theoretical point of view, A and B must be equal to 
$1 / t_{\text {res. }}$ For Ar we obtained a good agreement. It means that the gas is ideally mixed in the empty reactor.

As far as the gas transport in the reactor loaded with $0.01 \mathrm{~g}$ of the $\mathrm{Au} / \mathrm{TiO}_{2}$ porous catalyst is concerned, we assumed that interparticles diffusion must be much larger than intraparticles diffusion (as only a small amount of the catalyst is loaded in the same volume of the reactor, the bed porosity is almost as high as for the empty reactor). Therefore, the difference between $t_{\text {res }}$ of $\mathrm{Ar}$ in the reactor loaded with $0.01 \mathrm{~g}$ of $\mathrm{Au} / \mathrm{TiO}_{2}$ and $\mathrm{t}_{\text {res }}$ of $\mathrm{Ar}$ in the empty reactor must be due to the diffusion inside catalyst particles. The difference in Fig. 4 was about $0.112 \mathrm{~s}$ at $300 \mathrm{~K}$ and for $\mathrm{r}_{\mathrm{p}}=5.1 \times 10^{-4} \mathrm{~cm}$, and particle porosity of 0.12 the diffusivity inside the catalyst particles, $\mathrm{D}_{\mathrm{p}}$, was $1.4 \times 10^{-7} \mathrm{~cm}^{2} \mathrm{~s}^{-1}$, in good agreement with values reported in literature [27].

By increasing the weight of the sample in the micro-reactor from $0.01 \mathrm{~g}$ to $0.03 \mathrm{~g}$, we observed that a tremendous change of the Ar pulse response shape occurred over the range of the sample weight as shown in Fig. 5. By increasing the sample weight, the interparticle resistance to gas transport became important in addition to the intraparticle resistance. For small amounts of catalyst $(0.01 \mathrm{~g}$ and $0.016 \mathrm{~g})$ narrow pulse responses were obtained, and a longer tailing occurred due to the Ar low diffusion in and out of the pores, while the maximum of the curve remains essentially unchanged at about $200 \mathrm{~ms}$. A further increase of the sample weight $(0.024 \mathrm{~g}$ and $0.03 \mathrm{~g})$ resulted in a shift of the curve maximum to longer time and in a broadening of the response curves. As far as we know, it is for the first time that this kind of TAP experiments have been used to determine the intraparticle diffusivity. In view that this new method for the calculation of intraparticle diffusion coefficients becomes advertised, additional experiments over the same catalyst $\left(\mathrm{Au} / \mathrm{TiO}_{2}\right)$ in at least two different sieve fractions are envisaged. In this way, the diffusivity through the fixed bed becomes altered while the intraparticle diffusivity remains almost constant. Processing the different 
obtained pulse responses in the suggested way should therefore yield the same value for the intraparticle diffusion.

\subsection{Pump-probe pulse experiments}

In order to study the carbon monoxide oxidation reaction on the conventional $\mathrm{Au} / \mathrm{TiO}_{2}$ catalyst and to determine the active oxygen species, we have performed pump-probe (or alternating) pulse experiments. In the pump-probe pulse experiments a reactant is pulsed first (pump), then another reactant (probe) is pulsed after a given time interval. When oxygen was the pump molecule and carbon monoxide was the probe molecule, the lifetime of surface oxygen intermediates for the carbon monoxide oxidation was determined by measuring the carbon dioxide product yield as a function of the pump-probe time interval. By taking pumpprobe experiments at different temperatures we have also studied the influence of temperature on the reaction yield.

At $300 \mathrm{~K}$ only a small amount of $\mathrm{CO}_{2}(\mathrm{CO}$ conversion about $1 \%)$ was formed when $\mathrm{O}_{2}$ and $\mathrm{CO}$ were pulsed at the same time. By increasing the pump-probe time interval no increase in the product yield was observed. It means that no activated oxygen adsorption occurs, in good agreement with the oxygen adsorption studies. A small amount of $\mathrm{CO}_{2}$ formation was observed by the $\mathrm{O}_{2}$ pump - $\mathrm{CO}$ probe experiments. The $\mathrm{CO}_{2}$ production increased monotonically with temperature, but the value of $t_{p}$ and the pulse shape varied slightly with temperature. These small variations indicate that carbon dioxide adsorbs weakly on the catalyst surface. If strong adsorption occurred, as in the case of $\mathrm{Au} / \mathrm{Ti}(\mathrm{OH})_{4}{ }^{*}$, the average surface lifetime of $\mathrm{CO}_{2}$ would have exhibited a strong variation with temperature, resulting in large changes of $t_{p}$. The maximum amount of $\mathrm{CO}_{2}$ product was formed at $400 \mathrm{~K}(\mathrm{CO}$ conversion about $18 \%$ ) and for the case in which $\mathrm{CO}$ and $\mathrm{O}_{2}$ were pulsed together. But the 
product yield decreased with increasing pump-probe time intervals as shown in Fig. 6. It means that oxygen is weakly adsorbed on the surface. As the time interval between the two pulses (pump and probe) increased, oxygen tended to desorb from the surface before carbon monoxide was pulsed. In the case of $\mathrm{Au} / \mathrm{Ti}(\mathrm{OH})_{4}{ }^{*}$ catalyst, the $\mathrm{CO}_{2}$ yield presented a maximum at a given pump-probe time interval. $\mathrm{On} \mathrm{Au} / \mathrm{T}(\mathrm{OH})_{4}{ }^{*}$ oxygen strongly adsorbed and it took time to be transformed to an active $\mathrm{O}_{2}{ }^{-}$species $[7,21-23]$.

As the surface lifetime of active oxygen was so short, we think that oxygen adsorbs molecularly and weakly on the $\mathrm{Au} / \mathrm{TiO}_{2}$ surface. The observation is consistent with the TAP study on $\mathrm{O}_{2}$ adsorption as mentioned above. Fig. 6 also clearly shows that the newlydeveloped $\mathrm{Au} / \mathrm{Ti}(\mathrm{OH})_{4}{ }^{*}$ catalyst is more active than the conventional $\mathrm{Au} / \mathrm{TiO}_{2}$ catalyst and the behavior of the two catalysts is different with the oxygen adsorption. Moreover, the presence of $\mathrm{CO}$ affected neither the shape nor the intensity of the $\mathrm{O}_{2}$ response significantly when both gases were pulsed together.

An explanation for the behavior might be referred to the slower diffusion of $\mathrm{O}_{2}$ on the conventional catalyst due to the small radii of the micro-pore resulting in the adsorption of a small amount only of $\mathrm{O}_{2}$ on the internal surface.

To check the influence of internal diffusion, the reactant gases in mixture with a carrier gas (He) were continuously fed in the micro-reactor. We observed that the $\mathrm{CO}_{2}$ yield was not influenced by the flow rate of the carrier gas. This proved that the external mass transport is less important than the internal one in determination of the overall rate of catalytic carbon monoxide oxidation. 


\subsection{Oxygen isotope exchange}

Single-pulse and alternating pulse experiments using ${ }^{18} \mathrm{O}_{2}$ and $\mathrm{C}^{16} \mathrm{O}$ were performed at 300 , 400 , and $600 \mathrm{~K}$. Fig. 7 presents the dimensionless exit flows of the three oxygen isotopomers $\left({ }^{16} \mathrm{O}_{2},{ }^{16} \mathrm{O}^{18} \mathrm{O}\right.$, and $\left.{ }^{18} \mathrm{O}_{2}\right)$ at $400 \mathrm{~K}$ when a mixture of ${ }^{18} \mathrm{O}_{2},{ }^{16} \mathrm{O}^{18} \mathrm{O}$ and ${ }^{16} \mathrm{O}_{2}$ was pulsed on $\mathrm{Au} / \mathrm{TiO}_{2}$. The normalization of the experimental exit curves was made by dividing the response curve with the height of the peak. As all the species have the same $t_{p}$, it is concluded that no oxygen exchange occurs on the catalyst. The ratio between the three isotopomers was almost the same as the initial composition in the isotope mixture. If $\mathrm{O}_{2}$ dissociated to atomic oxygen at the catalyst surface, oxygen-isotope exchange with lattice oxygen atoms would have occurred.

As expected, almost only $\mathrm{C}^{16} \mathrm{O}^{18} \mathrm{O}$ isotopomer was observed and the pump-probe experiments revealed no variation of the product yield with pump-probe time intervals. Therefore, on the $\mathrm{Au} / \mathrm{TiO}_{2}$ catalyst, the lattice oxygen is not involved in oxygen exchange with $\mathrm{CO}_{2}$ formed by the $\mathrm{CO}$ oxidation reaction, which is entirely different from the case of $\mathrm{Au} / \mathrm{Ti}(\mathrm{OH})_{4}{ }^{*}$ catalyst $[21,22]$.

\section{Conclusion}

In an attempt to explain why the catalytic activity for low-temperature carbon monoxide oxidation of the newly-developed titania-supported gold catalyst, $\mathrm{Au} / \mathrm{Ti}(\mathrm{OH})_{4}{ }^{*}$, is much higher than that of the conventional catalyst, $\mathrm{Au} / \mathrm{TiO}_{2}$, the TAP single-pulse and pump-probe experiments on $\mathrm{Au} / \mathrm{TiO}_{2}$ have been performed. Our previous TAP results on $\mathrm{Au} / \mathrm{Ti}(\mathrm{OH})_{4}{ }^{*}$ have been compared with those on $\mathrm{Au} / \mathrm{TiO}_{2}$. Despite the fact that the conventional $\mathrm{Au} / \mathrm{TiO}_{2}$ 
catalyst has a higher surface area, as it has a microporous structure, the resistance to pore diffusion is higher. Therefore, the catalytic carbon monoxide oxidation reaction predominates on the external surface area and the internal surface area would not be utilized efficiently. Regarding the adsorption of $\mathrm{CO}, \mathrm{O}_{2}$, and $\mathrm{CO}_{2}$ on $\mathrm{Au} / \mathrm{TiO}_{2}$, the TAP experiments revealed the reversible and weak adsorption of all these molecules, while the TAP experiments on $\mathrm{Au} / \mathrm{Ti}(\mathrm{OH})_{4}{ }^{*}$ revealed the irreversible and strong adsorption of $\mathrm{O}_{2}$ and a reversible and weak adsorption of CO. For both catalysts, lattice oxygen atoms were not involved in the catalytic carbon monoxide oxidation reaction, and oxygen was adsorbed molecularly on the support. Using a small amount of catalyst sample, the intraparticle diffusion could be separated from the interparticle diffusion and the intraparticle diffusivity could be determined. The intraparticle diffusion coefficient was determined through singlepulse experiments in the presence of inert gases. The differences in the catalytic performances between $\mathrm{Au} / \mathrm{Ti}(\mathrm{OH})_{4}{ }^{*}$ and $\mathrm{Au} / \mathrm{TiO}_{2}$ is due to several factors including the amount and nature of oxygen defects on the supports on which $\mathrm{O}_{2}$ is transformed to active $\mathrm{O}_{2}{ }^{-}$species $[7,22,23]$, gold particles size, gold precursor-support interaction, but, as our TAP studies show, the nature of support through its morphology and specific surface area have an important influence on the performance of low-temperature carbon monoxide oxidation.

\section{Acknowledgement}

We acknowledge to Dr. H. Liu and Dr. A.I. Kozlov for preparation of the catalysts and to Dr. T. Shido for technical help. This work has been supported by Core Research for Evolutional Science and Technology (CREST) of Japan Science and Technology Corporation (JST). 


\section{Nomenclature}

$\mathrm{D}_{\mathrm{L}} \quad$ effective Knudsen diffusivity in the catalyst bed, $\mathrm{cm}^{2} \mathrm{~s}^{-1}$

$\mathrm{D}_{\mathrm{p}} \quad$ effective Knudsen diffusivity inside the particle, $\mathrm{cm}^{2} \mathrm{~s}^{-1}$

$\Delta \mathrm{H}_{\mathrm{ad}}$ heat of adsorption, $\mathrm{J}^{\mathrm{mol}}{ }^{-1}$

$1_{0} \quad$ length of the inlet section in front of the catalyst bed, $\mathrm{cm}$

$1_{0}{ }^{*} \quad$ equivalent length of the inlet section in front of the catalyst bed which only accounts for the empty space, $\mathrm{cm}$

$\mathrm{K}_{\mathrm{ad}} \quad$ adsorption equilibrium constants, $\mathrm{cm}^{3} \mathrm{~g}^{-1}$

$v$ pre-exponential factor for adsorption, $\mathrm{cm}^{3} \mathrm{~g}^{-1}$

L length of the catalyst bed, cm

$\mathrm{R}$ gas constant, $\mathrm{J}(\mathrm{mol} \cdot \mathrm{K})^{-1}$

$r_{p} \quad$ average particle size, $\mathrm{cm}$

$\mathrm{T}$ temperature, $\mathrm{K}$

$t \quad$ time, $\mathrm{s}$

$\mathrm{t}_{\text {res }} \quad$ mean residence time, $\mathrm{s}$

$t_{p} \quad$ time at which the exit flow is at maximum, $\mathrm{s}$

$\beta \quad$ porosity of the particles

$\varepsilon_{\mathrm{b}} \quad$ porosity of the catalyst bed

$\rho_{p} \quad$ density of the catalyst particles, $g\left(\mathrm{~cm}^{3}\right)^{-1}$ 


\section{References}

[1] M. Haruta, S. Tsubota, T. Kobayashi, H. Kageyama, M.J. Genet, B. J. Delmon, J. Catal. 144, (1993) 175.

[2] Y. Yuan, K. Asakura, H. Wan, K.Tsai, Y. Iwasawa, Chem. Lett. 25 (1996) 755.

[3] Y. Yuan, K. Asakura, H. Wan, K.Tsai, Y. Iwasawa, Cat. Lett. 42 (1996) 15.

[4] Y.Yuan, A.P. Kozlova, K. Asakura, H. Wan, K. Tsai, Y. Iwasawa, J. Catal. 170 (1997) 191.

[5] Y. Yuan, K. Asakura, A.P. Kozlova, H. Wan, K. Tsai, Y. Iwasawa, Catal. Today 44 (1998) 333.

[6] A.P. Kozlova, A. I. Kozlov, S. Sugiyama, Y. Matsui, K. Asakura, Y. Iwasawa, J. Catal. $181(1999) 37$.

[7] H. Liu, A.I. Kozlov, A.P. Kozlova, T. Shido, Y. Iwasawa, PCCP, 1 (1999) 2851.

[8] A.I. Kozlov, A.P. Kozlova, H. Liu, Y. Iwasawa, Appl. Catal. A 182 (1999) 9.

[9] G.C. Bond, D.T. Thompson, Catal. Rev.-Sci.Eng. 41 (1999) 319.

[10] G.C. Bond, D.T. Thompson, Gold Bull. 3341 (2000) 41.

[11] Y. Iwasawa, Stud. Surf. Sci. Catal. (Proc. 11th Int. Congr. Catal., Baltimore), 101 (1996) 21.

[12] F. Boccuzzi, A. Chiorino, S. Tsubota, M. Haruta, J. Phys. Chem. 100 (1996) 3625.

[13] M. Haruta, Catal. Today 36 (1997) 153.

[14] M.A. Bollinger, M.A. Vannice, Appl. Catal. B 8 (1996) 417.

[15] J.-D. Grunwaldt, C. Kiener, C. Woegerbauer, A. Baiker, J. Catal. 181 (1999) 223.

[16] J.-D. Grunwaldt, M. Maciejewski, O. S. Becker, P. Fabrizioli, A. Baiker, J. Catal. 186 (1999) 458.

[17] M. Haruta, N. Yamada, T. Kobayashi, S. Iijima, J. Catal. 115 (1989) 301. 
[18] M. M. Schubert, S. Hackenberg, A. C. van Veen, M. Muhler, V. Plzak, R. J. Behm, J. Catal. 197 (2001) 113.

[19] A. I. Kozlov, A. P. Kozlova, K. Asakura, Y. Matsui, T. Kogure, T. Shido, Y. Iwasawa, J. Catal. $196(2000) 56$.

[20] D.A.H. Cunningham, W. Vogel, R.M. Torres Sanchez, K. Tanaka, M. Haruta, J. Catal. $183(1999) 24$.

[21] M. Olea, M. Kunitake, T. Shido, K. Asakura, Y. Iwasawa, Bul. Chem. Soc. Jpn. 74 (2001) 255.

[22] M. Olea, M. Kunitake, T. Shido, Y. Iwasawa, Phys. Chem. Chem. Phys. 3 (2001) 627.

[23] H. Liu, A. I. Kozlov, A. P. Kozlova, T. Shido, K. Asakura, Y. Iwasawa, J. Catal. 185 (1999) 252.

[24] B.S. Zou, M.P. Duduković, P.L. Mills, J. Catal. 145 (1994) 683.

[25] O.P. Keipert, M. Baerns, Chem. Eng. Sci. 53 (1998) 3623.

[26] T.A. Nijhuis, L.J.P. van den Broeke, M.J.G. Linders, J.M. van de Graaf, F. Kapteijn, M. Makkee, J.A. Moulijn, Chem. Eng. Sci. 54 (1999) 4423.

[27] T.A. Nijhuis, L.J.P. van den Broeke, M.J.G. Linders, J.M. van de Graaf, F. Kapteijn, M. Makkee, J.A. Moulijn, Catal. Today 53 (1999) 189.

[28] J. T. Gleaves, G. S. Yablonskii, P. Phanawadee, Y. Schuurman, Appl. Catal. A 160 (1997) 55 .

[29] D.G. Huizenga, D.M. Smith, AIChE J. 32 (1986) 1.

[30] S. O. Shekhtman, G. S. Yablonsky, S. Chen, J. T. Gleaves, Chem. Eng. Sci. 54 (1999) 4371. 
Table 1. Kinetic Parameters for $\mathrm{O}_{2}$ and $\mathrm{CO}$ adsorption over $\mathrm{Au} / \mathrm{TiO}_{2}$

\begin{tabular}{|c|c|c|c|c|}
\hline Species & Temp (K) & $\mathrm{K}_{\mathrm{ad}} \times 10^{3}\left(\mathrm{~cm}^{3} \mathrm{~g}^{-1}\right)$ & $v\left(\mathrm{~cm}^{3} \mathrm{~g}^{-1}\right)$ & $-\Delta \mathrm{H}_{\mathrm{ad}}\left(\mathrm{kJmol}^{-1}\right)$ \\
\hline \multirow{3}{*}{$\mathrm{O}_{2}$} & 300 & 7.02 & \multirow{3}{*}{0.011} & \multirow{3}{*}{2.3} \\
\hline & 400 & 5.32 & & \\
\hline & 600 & 4.46 & & \\
\hline \multirow{3}{*}{$\mathrm{CO}$} & 300 & 8.01 & \multirow{3}{*}{0.066} & \multirow{3}{*}{9.2} \\
\hline & 400 & 7.58 & & \\
\hline & 600 & 1.29 & & \\
\hline
\end{tabular}


Figure Captions

Fig.1. Unit area normalized exit flow (solid line) and model-predicted (broken line) transient responses for $\mathrm{Ar}$ on $\mathrm{Au} / \mathrm{TiO}_{2}$ and the experimental and model-predicted (dot-solid line) transient response for $\mathrm{Ar}$ on $\mathrm{Au} / \mathrm{Ti}(\mathrm{OH})_{4}{ }^{*}, 0.03 \mathrm{~g}$ catalyst sample, at $300 \mathrm{~K}$.

Fig.2. Unit area normalized exit flow (solid line) and model-predicted (broken line) transient responses for $\mathrm{He}$ on $0.03 \mathrm{~g} \mathrm{Au} / \mathrm{TiO}_{2}$ at $300 \mathrm{~K}$.

Fig.3. TAP response curves on $0.03 \mathrm{~g}$ of $\mathrm{Au} / \mathrm{TiO}_{2}$ at $300 \mathrm{~K}$ : (A) $\mathrm{He}$, (B) $\mathrm{CO}$, (C) $\mathrm{O}_{2}$, (D) $\mathrm{CO}_{2}$, and (E) Ar.

Fig.4. Ar response curves in the TAP reactor without catalyst (a) and with $0.01 \mathrm{~g}$ of $\mathrm{Au} / \mathrm{TiO}_{2}$ (b).

Fig.5. Influence of the $\mathrm{Au} / \mathrm{TiO}_{2}$ weight on the Ar diffusion through the catalyst bed: (A) $0 \mathrm{~g}$, (B) $0.01 \mathrm{~g}$, (C) $0.016 \mathrm{~g}$, (D) $0.024 \mathrm{~g}$, and (E) $0.03 \mathrm{~g}$.

Fig.6. Relative $\mathrm{CO}_{2}$ product yields as a function of pump-probe time interval at $300 \mathrm{~K}$, $\mathrm{Au} / \mathrm{TiO}_{2}(\boldsymbol{\bullet})$, and $\mathrm{Au} / \mathrm{Ti}(\mathrm{OH})_{4}{ }^{*}(\bullet)$ and at $400 \mathrm{~K}, \mathrm{Au} / \mathrm{TiO}_{2}(\boldsymbol{\Delta})$.

Fig.7. Dimensionless response of oxygen isotopes ${ }^{16} \mathrm{O}_{2},{ }^{16} \mathrm{O}^{18} \mathrm{O}$, and ${ }^{18} \mathrm{O}_{2}$ when a mixture of ${ }^{18} \mathrm{O}_{2}$ (major) $+{ }^{16} \mathrm{O}_{2}+{ }^{16} \mathrm{O}^{18} \mathrm{O}$ was pulsed on $0.03 \mathrm{~g} \mathrm{Au} / \mathrm{TiO}_{2}$, at $400 \mathrm{~K}$. 


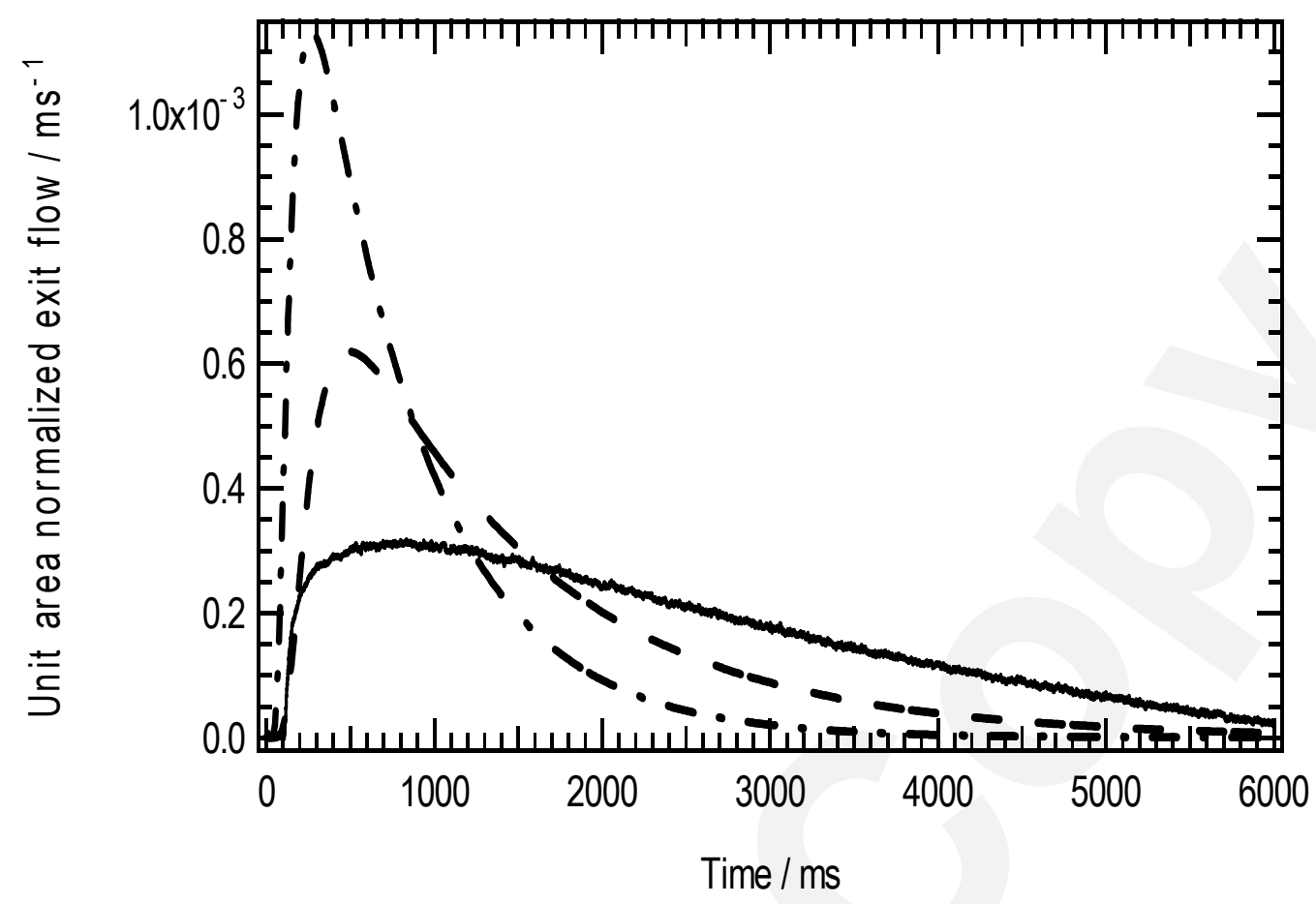




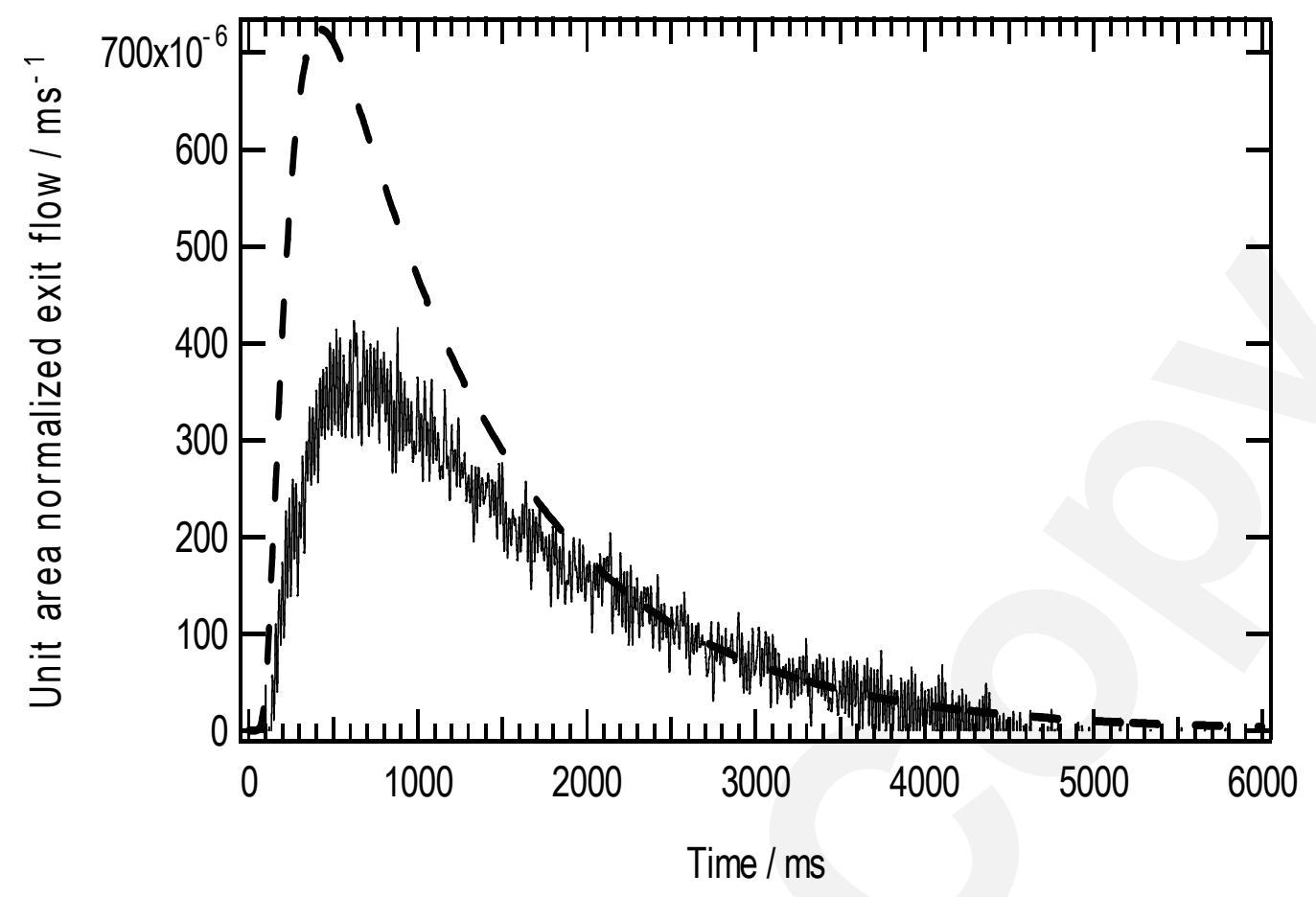




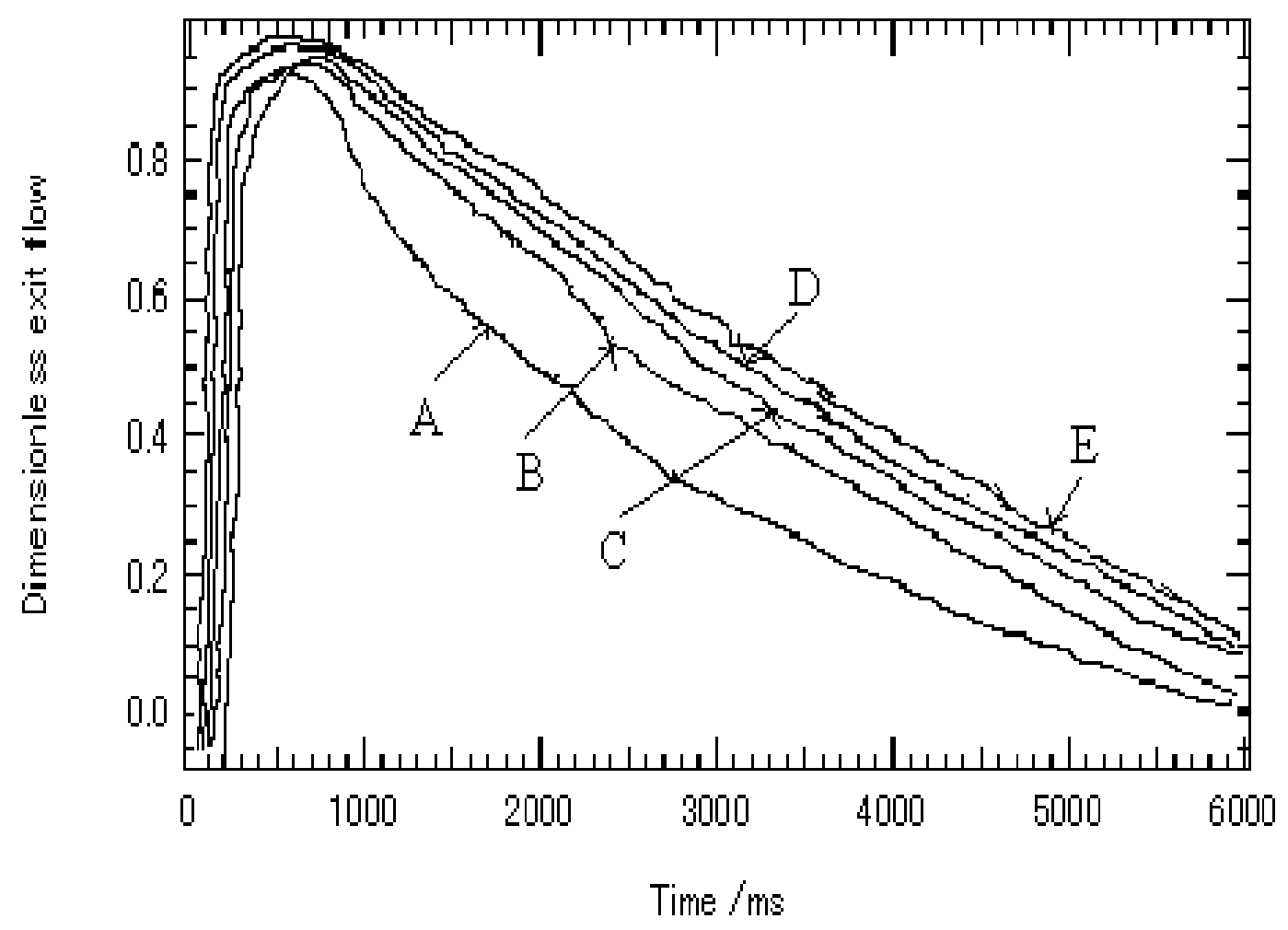




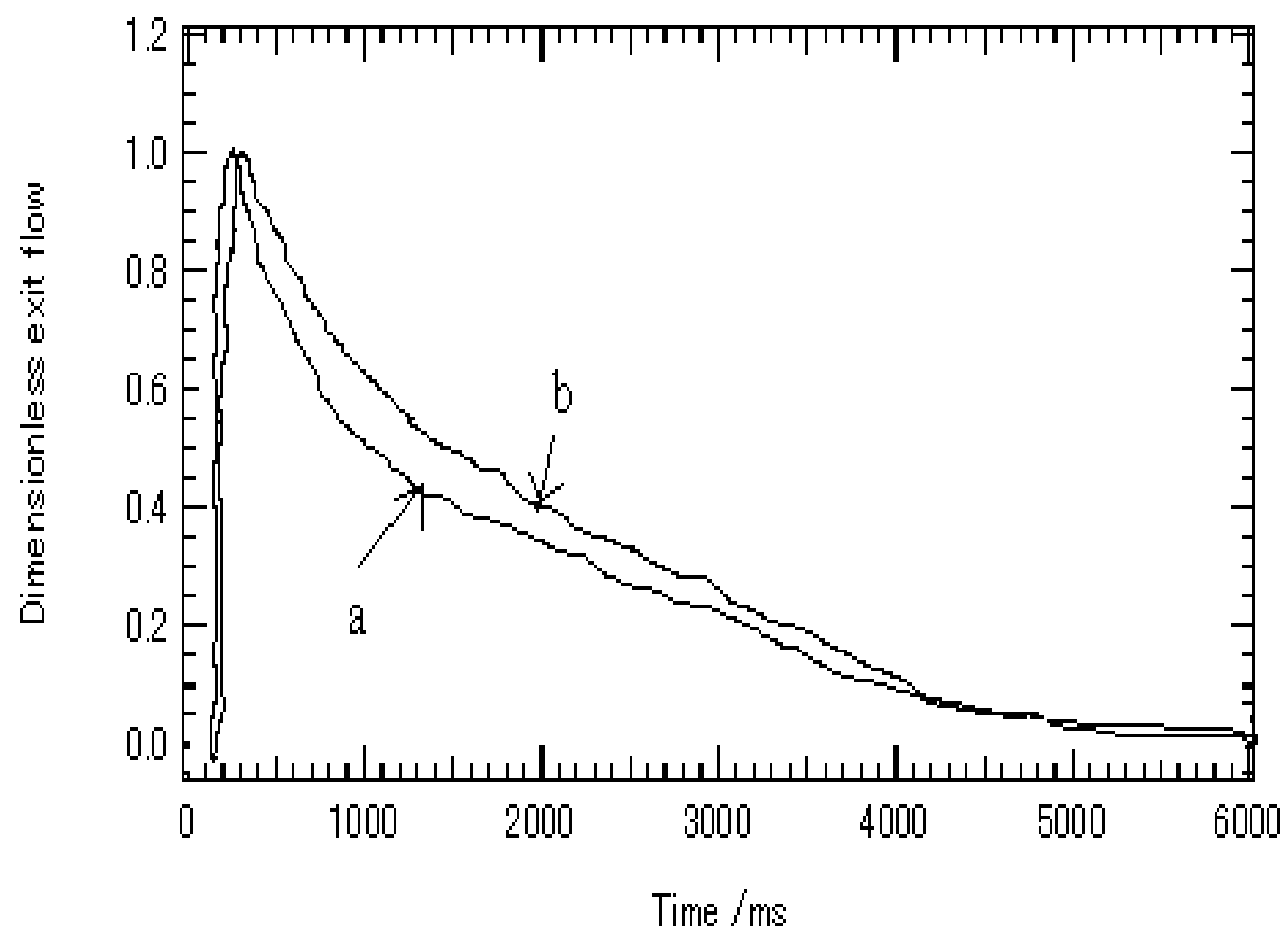




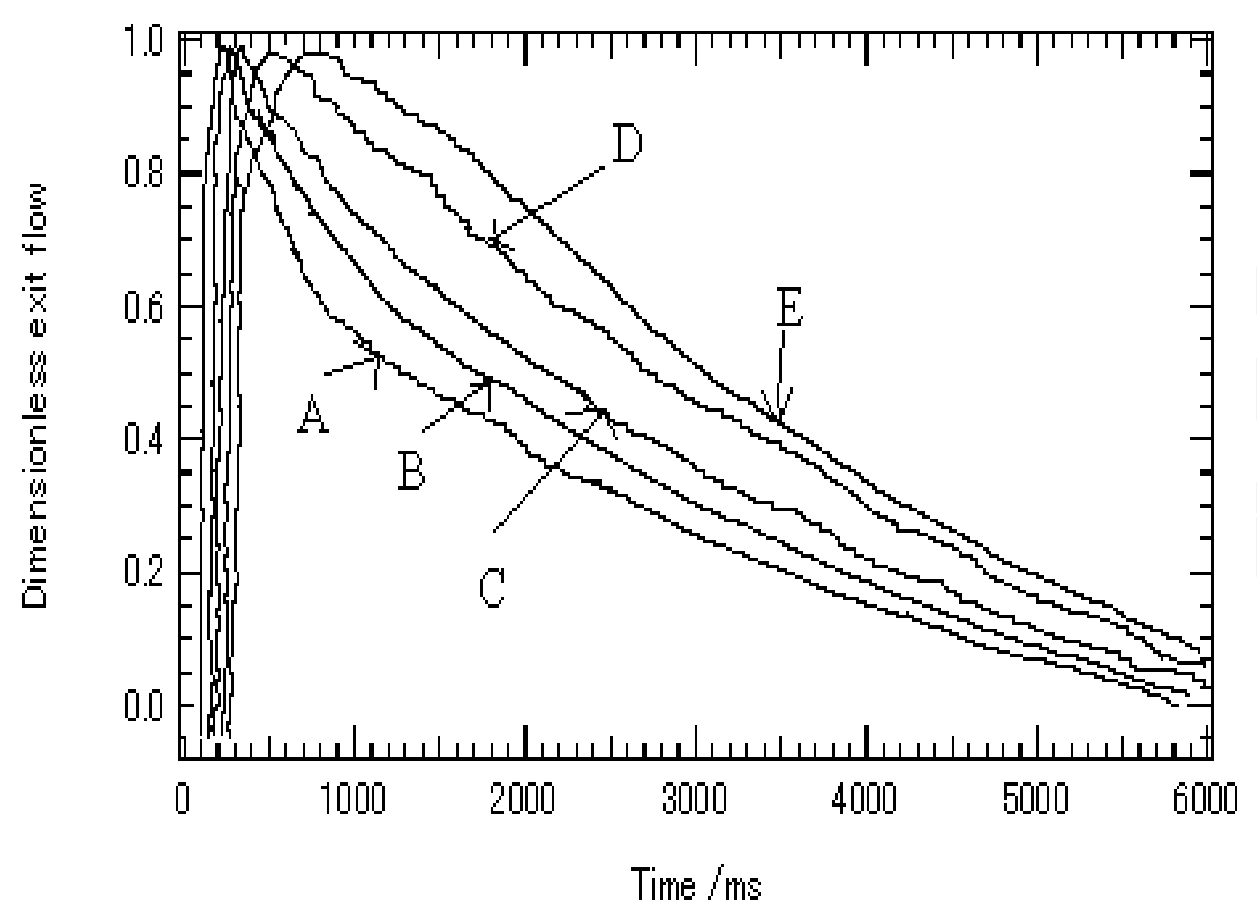




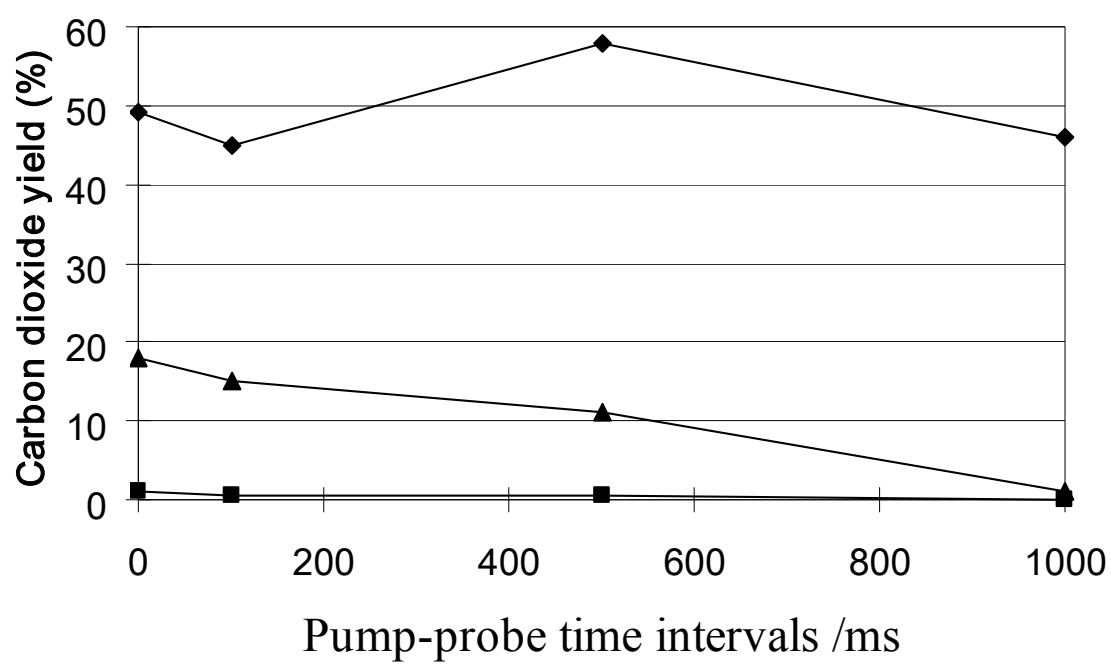




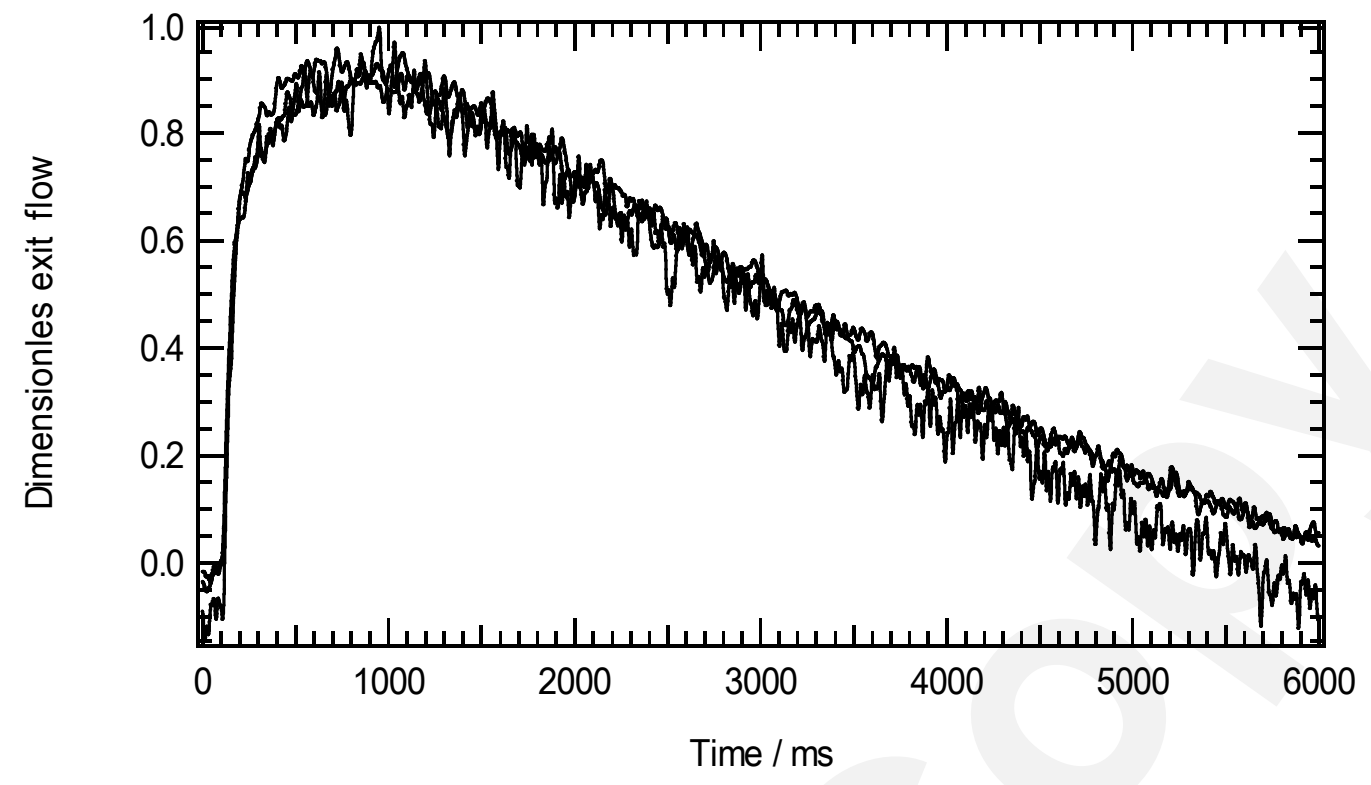

